\title{
Chapter 2 \\ Scale in Nature-Based Solutions \\ for Flood Risk Management
}

\author{
Pavel Raška, Lenka Slavíková and John Sheehan
}

\section{Introduction}

Nature-based solutions (NBS) have recently spread to the flood risk management (FRM) agenda as potentially efficient and sustainable measures to reduce the susceptibility to and impacts of various kinds of floods, including riverine floods, flash floods and storm surges. In this context, some authors urge for a deeper understanding of the hydro-ecological effects of NBS on different scales and for the diversity of environmental conditions (Schanze 2017; Nesshöver et al. 2017). At the same time, suitable institutional scales for effective implementation of NBS in different legal settings must also be set up. If these two approaches, hydro-ecological and institutional, shall work together and facilitate the implementation of NBS in FRM, it is crucial to understand the different meanings of scale across the disciplines that are involved in FRM.

Only few concepts used in both social and environmental sciences have merited such critical reflection and extreme controversies during the past decades as the issue of scale (Marston et al. 2005). At the same time, similarly few concepts may affect the effectiveness and efficiency of the environmental management as much

P. Raška (ه)

Department of Geography, Faculty of Science, J. E. Purkyně University in Ústí nad Labem, Usti nad Labem, Czech Republic

e-mail: pavel.raska@ujep.cz

L. Slavíková · J. Sheehan

Faculty of Social and Economic Studies, Institute for Economic and Environmental Policy

(IEEP), J. E. Purkyně University in Ústí nad Labem, Usti nad Labem, Czech Republic

e-mail: lenka.slavikova@ujep.cz

J. Sheehan

e-mail: John.Sheehan@uts.edu.au

J. Sheehan

Faculty of Society and Design, Bond University, Gold Coast, Australia

T. Hartmann et al. (eds.), Nature-Based Flood Risk Management on Private Land, https://doi.org/10.1007/978-3-030-23842-1_2 
as scale does (Cumming et al. 2006). The aim of this chapter is to introduce the roots of various conceptualizations of scale, the way they are encountered, and the implications different views of scale may have on the use of NBS in FRM.

The literature currently available on issues of scale is generally grounded in geography and spatial science, but also crosses into environmental management, economics and other disciplines such as law. In FRM, scale has been widely discussed in the context of a range of issues, starting with a priori flood risk assessment and pointing to differential methodologies, use of flood risk assessment and uncertainties across scales (de Moel et al. 2015; Gusyev et al. 2016), extending to issues of restoration efforts aimed at improvement of overall river quality (Muhar et al. 2016). Among the studies, the theoretical work on scale in complex socio-ecological systems and on scale mismatches has fundamental implications for effectiveness and efficiency of FRM using the NBS - this will be mainly addressed in this chapter.

Scale in complex socio-ecological systems is directly impacted by the specificity of a chosen nature-based solution in FRM which, in turn, is similarly impacted by the particularity of the overarching property laws and especially, local land uses and property ownership patterns. Specificity of a FRM solution and particularity in local land tenure are not unexpected but rather indispensable contemporaneous fundamentals when determining how suitable a scale is. This can help to avoid scale mismatches.

Therefore, the ambition of this chapter is not to summarize the knowledge on scale nor to develop new concepts of the term. Rather-since the chapter should serve as a prelude to case studies presented later on-our aim is to provide a comprehensible essay on scale, explain the fundamentals of its nature and discuss its implications for NBS in FRM. We will endeavour to follow an interdisciplinary perspective and to make use of various examples from history, geosciences and social sciences to introduce readers to complexities of scale. First, we will discuss the two views of scale, which are the epistemic and ontological ones, and will point out that scale does not only relate to space but also to time, and that a change in any of these dimensions may incur a change in the other one. Second, drawing from these considerations, we will then discuss issues of downscaling and upscaling, as these are crucial in turning the experimental and/or theoretical research results into practice. Finally, we will summarize major constraints one encounters in managing socio-ecological systems such as NBS in FRM and resulting from the different conceptualizations of scale.

\section{Nature of Scale in Nature-Based Solutions}

\section{Epistemic View of Scale}

Practitioners seeking for a definition of scale in traditional dictionaries may remain frustrated in their effort. The online version of Merriam-Webster dictionary, for instance, defines scale in its conventional connection to weights and therefore denotes 
its original purpose to compare the Newtonian properties of the material world. It will be shown later on that such understanding of the scale may be relevant for many bioecological and biophysical studies that make use of the so-called geometrical scale. However, while absolutely necessary in our daily life (take just health care or shopping as examples), this perspective reduces the reality, because it assumes that all things may be compared in an objective manner. But what we already know is that some realities are rather relative and - in a social domain — may be differently evaluated by people and institutions (not) involved. To describe the reality in such manner, we usually refer to human-geographical or sociological scale as the representation of reality (Gregory et al. 2009; Mayhew 2015).

From this perspective, scale is a fundamental measure through which we perceive and understand the world around us (Lynch 1960). Imagine a small child walking through the crowded town and perceiving the surroundings from an eye-height of less than a meter, for instance. As this child escapes a jumble of legs surrounding it, it sees the far horizons of streets with buildings so high that it must bend backwards to see their facades and to orient itself within the known and unknown world. The adults, in turn, are well oriented all the time, but it may easily happen that they lose sight of their children or even bump into them. Globally, we recall the notion of intangible indigenous cultural knowledge (Office of Environment and Heritage 2017) wherein some savanna tribes in sub-Saharan Africa, and in particular Australian aboriginal peoples, are remarkably well orientated in their vast African or Australian grasslands. Alternatively, those Indigenes would almost certainly feel very disorientated in the dense primeval highland forests of Papua-New Guinea.

What this basic distinction between geometrical and geographical or sociological space illustrates is the epistemic view on scale, both in terms of practice (shaping the world around us) and of the research communication (targeting our research and finding a common language). Therefore, the epistemic dimension of scale expresses its function in terms of our orientation in the world, but, at the same time, it denotes how the space around us is socially constructed and how it may be consumed and reproduced (Brenner 2001). Further examples of such relativity of scale may be found in history. Until the last third of the 20th century, many historians were extensively addressing the landscape histories by converting the old units to the metric system. It was a well-known Russian historian A. J. Gurevic (1985), however, who pointed out the social construction of these old units early on. For instance, the medieval measures of fields in England were expressed as an expanse that may be ploughed by eight oxen in a season, and in Czech lands, the area of meadows was expressed as the number of drays necessary to transport all the yielded grass. Neither of these units was normalized, and both differed across regions significantly. Yet, both of them provided people with clear impression of the size, resolution and dimension since these units related to peoples' daily practices (see also Alfonso 2007).

A discussion of how various factors and agents interact at various scales is forthcoming. However, the very first implication we may present now for implementation of NBS in FRM is this: different stakeholders scale a certain space differently. In a large catchment, for instance, if river basin authorities were to design a flood retention measure on a few hectares in order to reduce the riverine floods, this may seem too 
extensive for a landowner if this comprises almost the whole of his/her land. Meanwhile it would only represent a small piece of the intended effort for the authorities. For NGOs that helped during the negotiation process, it may be a great story of success. In contrast, the landowner who designed the measures on his/her private land may be well satisfied with their effect, while the river basin authorities may not consider such measures as relevant to their catchment-scale effort (Slavíková and Raška-Part II, Chap. 2; the role of scale in multilevel management is generally discussed by Termeer et al. 2010).

Until now, we were talking about spatial scale, but issues of scale similarly relate to time. Much of the social construction of time is constrained by the level of our knowledge. Following this way of argumentation we may notice, for example, that with growing number of available data sources towards present days, the historical periods established by historians are becoming shorter. Historians of modernity may also exploit the fascinating potential of oral history, thus gaining a very variegated view of the near past as compared to the ancient times; so their descriptions of the past (with some exceptions) are becoming more detailed. Furthermore, there is certainly not a single definition of the historical periods across the continents, or even the regions, that also denotes how time is considered in various cultures. Thus, Green (1995), for instance, has shown that eras of the world's history tend to reflect our priorities and values, while raising political questions and concerns.

What makes all these time-scale considerations relevant to our topic is, that space and time do not only form a duality but a rather intertwined and complex time-space complexities (Hägerstrand 1970). This is because changing the time dimension may alter how things are organized and interdependent in a spatial dimension, and vice versa. Harvey (1989) introduced the apt term of time-space compression to describe how space was reduced with Man's increasing activity radius throughout history. This also implied the growing speed of social processes. For instance, in spite of various feedbacks and control mechanisms, some institutions or individuals currently possess the competence and ability to significantly affect our world in only a few short minutes. On the other hand, there still are extensive communities that may have almost negligible influence on institutional structures they live in, or their effort would only produce slow or delayed structural changes that will not immediately address the critical issues faced by these communities (cf., Giddens 1984).

The implication of the epistemic view of the time scale (chronology) and of the time-space complexity for FRM is twofold. First, as the perceived time dimension may lead (and often does) to categorizing landscape processes in terms of stability and instability, it may result in misperceptions of fluvial hazards (Schumm 1994) in turn. According to this view, some disturbing processes (e.g., floods) are wrongly perceived as solely non-natural and rapid, while certain human-induced changes may be perceived as everlasting. In other cases, the longevity (see further text) may be expected as a fundamental property of man-made FRM interventions (e.g., the smallscale NBS discussed in Matczak-Part II, Chap. 1). Such a perception of stability may then influence the decision about their implementation if these measures are finally evaluated as unstable. Second, the epistemic view of time-space complexities 
points to the increasing variability of speed and extent with and to which institutions and individuals may make their decisions about flood risk and land management.

\section{Ontological View of Scale}

The notion of subjectivity in perception of space and of relativity of scale inevitably begs the question whether any kind of scale-based organization of reality independent of our minds exists in bioecological/biophysical and social systems. Or, being consistent with our terminology above, how relevant is the ontological view of scale? In scholarly literature, this question is usually addressed in two directions (Herod 2003). First, whether-generally speaking — the links through which objects and processes are related change across scales, and second, whether any ontological scales exist, such as global and local, independent of our construction of space.

Some scientists would probably argue that ontological scale is more characteristic of the bioecological and biophysical domain (e.g., Cumming et al. 2006). Although some of the sole physical objects and features may display similarities across scales (well explained by the fractal theory), links among such objects and features may be subject to variations when seen through changing time-scale prisms, in fact. Such variations are widely discussed in biology, ecology or geomorphology. In their seminal paper, Schumm and Lichty (1965) addressed interdependencies of variables in the river drainage systems and showed how dependent variables may become independent when seen in different time frames, and vice versa. In other words, the causation among variables may differ within the time and spatial scale. Therefore, rather than being simply hierarchical, various features and processes may exhibit differently set continuities (Marston et al. 2005) and feedbacks across space and time.

Another illustration of variations in the organization of bioecological and biophysical features stems from their adaptability. While some features may display a high potential for changes, others-and viewed on different scales-evince inertia caused by negative feedbacks, or their modifications are constrained by physical, chemical and biological laws that do not allow for a significant change. These differences, characterized as longevity of socio-ecological systems and subsystems (Costanza and Folke 1996, p. 21), should frame our evaluation of sustainability of environmental management measures, including FRM.

The second question, whether ontological categories of scale such as global and local exist, is subject to intense debates (Herod 2003; Marston et al. 2005). In any case, both social sciences and geoscience tradition would probably admit that what makes an agent or a process global is not a priori its size but largely depends on the strength of its causal links to influences on the global system (Wilbanks and Kates 1999). Typically, extreme increases in the quantities of greenhouse gases produced by only a couple of countries are considered the main factor contributing to global climate change, including growing extremes in weather pattern, rising sea levels and resulting social impacts (Sheehan 2014). The existence of social and economic ties established by a strong or innovative leader or a firm can have the capacity to influence 
a global production network and/or diffusion of innovation in such a way that local economies may be significantly affected (Ernst and Kim 2002). Nevertheless, neither of these examples must imply the uniformity of impact caused on a local scale. This justifies the current study of regional environmental change or regional resilience under external shocks.

With respect to FRM, the ontological view of scale suggests that (a) tailored measures must be considered for individual spatial domains, taking into consideration that FRM measures at one scale and for certain flood types may exhibit different and perhaps contradictory effects at another scale and for different types of floods. Such spatiotemporal changes in the effects of FRM measures are, to a large degree, effects of duality in view of land as a social (legal) institution and as a natural entity, as will be discussed in the last section of the chapter. In reference to the variability of scales, (b) attention must be paid to the transferability of expert knowledge from one scale to another. Finally, (c) any process and agent (landowner, municipal authorities, river basin authorities, NGOs) cannot be implicitly considered local because of its apparent size or 'root location'-simply, the scale of actions and impacts of the locally-rooted natural and social processes may display distinct variation, given inherent linkages to higher spatial scales. For example, local polders-if welldesigned - may have impacts on a catchment exceeding their own spatial extent; the blue-green infrastructure-if sufficiently connected-may influence microclimatic patterns (Louda and Macháč_-Part III, Chapter 1), and even one leader may influence the decision-making in the whole catchment depending on his or her communication skills, networks and his or her ability to mobilize available lay knowledge.

\section{Upscaling or Downscaling in Flood Risk Management?}

The discussion above opens a crucial question: what is the right and available way to shift our knowledge and practice between scales? This means, how should the processes of upscaling and downscaling in FRM be addressed? Before trying to find an answer, however, our and any practitioner's thoughts should finally determine if and why it is important to downscale and upscale the FRM measures, including the NBS. While downscaling may be easily supported with a necessity of involving local stakeholders, the intriguing question is if and why bigger is considered better in FRM (note that bigger does not stand for "uniform" here and in the following text). There are several arguments (Buijse et al. 2002; Adger et al. 2005; Zevenbergen et al. 2008) that justify the environmental rationale for extensive FRM measures, taking into account the complementarity of their direct hydrologic effects and indirect effects on ecosystem services (Schanze 2017).

Generally, both ecological and economical studies suggest that open systems with existing multiple links are more resilient and have a higher performance in a longterm perspective although they may suffer from short-term external disturbances. For example, although gross domestic product decreased and the unemployment rate rose in many countries during and after the global economic crises in 2007-2008, 
the speed of recovery and current economic performance of these countries is still higher than that experienced by semi-open/closed totalitarian economies. Similarly, although depending on scales, the effect of external disturbances seems to be more visible in regions of industrial specialization than those with economic diversity (Ženka et al. 2015). In an ecological domain, it was argued that broad-scale programmes may be more efficient because they make use of environmental variation in order to compensate for local or temporary risks (e.g., water scarcity, accelerated sedimentation during floods, land degradation; e.g., Cumming et al. 2006).

Various methods have been developed to understand the uncertainties resulting from transfer of the site-specific or experimental laboratory research results to broader scales or to design a multi-scale hierarchical research that would clarify the variances of bioecological, biophysical and social processes across scales. Among these methods, two approaches are the most frequent (cf., Burt 2003). The statistical approach uses a generalization based on filtering or geostatistical analyses in order to remove small-scale noise and to emphasize the general statistical patterns (trends and fluctuations). This approach may be partly useful when attempting to upscale patterns of individual features and processes, such as flood frequency analyses or changing social vulnerability to floods from time-series. It would be insufficient, however, for the study of complex causal links within the socio-ecological systems, because the nature of such links may exhibit variances across scales (see above). In fact, apparently small-scale noise or a dependent variable at a local scale may represent independent or causal variables at other spatial and time scales.

Another approach to the multi-scale hierarchical research and to upscaling its results for practical issues is a nested experiment design. This approach resolves two troubles faced by statistical approaches: first, it establishes an a priori hierarchical (quasi-continual) design, thus not inferring the nature of processes at one scale from data gained at another scale; second, it overcomes the limits of financial sources and time to perform detailed empirical sampling over the vast areas. The nested approach stems from the assumption that by looking at various scales (study plots/areas) in one area that are close enough in order to study the links among each pair of neighbouring scales, we will finally be able to fill the gap between the two outer (smallest and largest) scales (Costanza and Folke 1996, p. 24).

\section{Scale Mismatch in Socio-ecological Systems}

Deriving from different views on scale and continuing to variations in physical and social processes across spatiotemporal scales, we have arrived at a critical step that limits the effort for implementation of NBS in FRM. In particular, if we accept the assumption that broad-scale NBS are beneficial for FRM and that approaches for upscaling our experience (with certain limits) to broader scales are available, we may pose a fundamental question: why do we still encounter such difficulties in the implementation of broad-scale NBS in FRM and why are well-documented good practice cases still so rare? 
Basically, the answer lies within the duality in the perception of ecological and social systems. While it is easy to understand that territorial integrity (or at least spatial density) of NBS for water retention will do a better job than site-specific and separated measures, the national and regional policies, land tenure models as well as property laws have resulted in extreme land fragmentation. As Freyfogle has stated, "one has to do with the mismatch between the way private land is portrayed in law and culture and the way it exists in real world of nature" (Freyfogle 2003, p. 7). In addition, in many political and tenure systems, such duality in the view of land would not only relate to private land but rather to the continuity between the public and the private. The fragmentation resulting from both the ownership and administrative division, in turn, limits the viability of broad-scale NBS if not all integrated FRM measures. By transforming land into a resource (Hanna and Jentoft 1996) people imply its differential values and set respective property rights to assure expected profits for stakeholders and owners (Freyfogle 2003, p. 242), thus disconnecting the social and ecological systems. Such disconnection builds a sharp divide in ways of argumentation for the right to access and benefit from shared environmental values (ecological services) provided by nature.

In an FRM context, such duality is illustrated when the suggested measures are upscaled based on empirical data that was gained at more detailed scales and in two domains with different scale dependencies. Some failures in FRM should then be considered to result from a mismatch between the scale of management and the scale of environmental variations (Gunderson and Holling 2002; Young 2002; Cumming et al. 2006). The mismatch is obvious at lowest administrative levels; for instance, where municipalities have gained fundamental (even though not sole) competencies in the past few decades (cf., the EU Floods Directive 2007/60/EC). Despite the arguments for the decentralization of FRM, it is now increasingly difficult to coordinate the ecologically relevant measures in catchments, which are fragmented across a number of administrative units (Moss and Newig 2010; Huesker and Moss 2015; Slavíková et al. 2019) and diversified into various FRM strategies and practices (Gilissen et al. 2016). The effects of land and institutional fragmentation will certainly differ for various flood types. It can be assumed that the administrative fragmentation will strongly affect the effectiveness of the FRM programmes aimed at riverine flood risk reduction. On the other hand, efforts aimed at flash flood risk reduction or storm surges in small semi-natural catchments or specifically in urban areas will increasingly face the ownership fragmentation, whereas the administrative fragmentation may be limited.

Accordingly with Cumming et al. (2006), we may postulate that scale mismatches may derive from the social domain (e.g., tenure systems, policies), the ecological domain (changing nature of processes across scales, see Sect. 2), but also from coupled social-ecological processes. In the social domain, what individuals expect and how do they decide in terms of their own property and their community, and what they expect from the government (NIMBY syndrome is only one example illustrating contradictory behavioural responses; see, e.g., Rand and Hoen 2017) is generally contradictory. Accordingly, flood risk reduction behaviour and decision-making will exhibit differences at the individual, municipal, catchment or national scale respec- 
tively. Also in the ecological domain may flood impacts imply significant variations (trade-offs) across scales. Flash floods may bring about necessary episodic local disturbances for the sake of the renewal of forest ecosystems upstream, but downstream deposits of high volumes of material may arrive, for instance. The mismatches resulting from a complex grid of spatiotemporal causes and of social and/or ecological domains will appear as primarily spatial, temporal or functional, but in all cases they will denote a situation where hierarchies of management and ecological processes are not aligned and do not allow for effective and efficient planning of FRM measures.

\section{Concluding Remarks on Realignment of Scale in FRM}

Considering the above discussed scale mismatches, FRM may be successful if it is conceived in an environment where the scale is capable of effective implementation within and respecting the existing land tenure system. For this reason, several researchers and planners have tried to find a viable common scale that would allow for social and political acceptance of FRM (e.g., a catchment scale or a municipal scale, the EU Floods Directive 2007/60/EC; Hartmann and Juepner 2014), and to discuss options for incremental and complex planning processes (cf., Lindblom 1959).

Realignment of scales to improve the FRM would be difficult for many reasons, however. First, determining the source of scale mismatch can be tricky when the physical processes are not well understood, competencies and agendas among institutions are not clearly defined, or possibilities to transform inherited policy practices are limited due to multiple path-dependencies in social, political and economic systems. In this context, the implementation of the EU Water Framework Directive (2000/60/EC) and the EU Floods Directive (2007/60/EC) represents the unique experiment of social and ecological re-scaling with (so far) uncertain effects on the resource quality and abundance (see Huesker and Moss 2015 or Jager et al. 2016 for detailed information).

For the above-listed reasons, it is of fundamental importance to reassess the options for upscaling NBS in FRM and reconsider them in terms of possible scale mismatches. If land uses and land ownership and management structures are not properly addressed, the effort for nature-based solution support in FRM will remain inefficient. Therefore, it seems that these policy objectives may only be reached if we broaden the available evidence about the hydro-ecological effects of NBS in FRM at various scales, while addressing acceptability and willingness to adopt these solutions at comparative institutional scales and under different legal regimes. Clearly, our ambition must be to explore the methodological options for an interdisciplinary approach within the individual studies in addition to fragmented hydro-ecological research, social inquiries or legal studies.

Acknowledgements We thank the Operational Programme Research, Development and Education of the Czech Republic for financing the project Smart City-Smart Region-Smart Community (grant number: CZ.02.1.01/0.0/0.0/17_048/0007435) that led to the present book chapter. 
Open access of this chapter is funded by COST Action No. CA16209 Natural flood retention on private land, LAND4FLOOD (www.land4flood.eu), supported by COST (European Cooperation in Science and Technology).

\section{References}

Adger WN, Arnella NW, Tompkins EL (2005) Successful adaptation to climate change across scales. Glob Environ Change 15(2):77-86

Alfonso I (ed) (2007) The rural history of medieval European societies-trends and perspectives. Brepols Publishers, Turnhout

Brenner N (2001) The limits to scale? Methodological reflections on scalar structuration. Prog Hum Geogr 15:525-548

Buijse AD, Coops H, Staras M, Jans LH, Van Geest GJ, Grit RE, Ibelings BW, Oosterberg W, Roozen FCJM (2002) Restoration strategies for river floodplains along large lowland rivers in Europe. Restor Ecol 47(4):889-907

Burt T (2003) Scale: resolution, analysis and synthesis in physical geography. In: Holloway SL, Rice SP, Valentine G (eds) Key concepts in geography. SAGE Publications, London/Thousand Oaks, pp 209-228

Costanza R, Folke C (1996) The structure and function of ecological systems in relation to propertyright regimes. In: Hanna S, Folke C, Maler KG (eds) Rights to nature. Island Press, Washington, DC, pp 13-34

Cumming GS, Cumming DHM, Redman CL (2006) Scale mismatches in social-ecological systems: causes, consequences, and solutions. Ecol Soc 11(1):14

de Moel H, Jongman B, Kreibich H, Merz B, Penning-Rowsell E, Ward PJ (2015) Flood risk assessments at different spatial scales. Mitig Adapt Strateg Clim Change 20(6):865-890

EU Floods Directive 2007/60/EC (2007) Directive on the assessment and management of flood risks. European Community

Ernst D, Kim L (2002) Global production networks, knowledge diffusion, and local capability formation. Res Policy 31(8-9):1417-1429

Freyfogle ET (2003) The land we share: private property and the common good. Island Press, Washington, DC

Giddens A (1984) The constitution of society. Outline of the theory of structuration. Polity, Cambridge

Gilissen HK, Alexander M, Beyers J-C, Chmielewski P, Matczak P, Schellenberger T, Suykens C (2016) Bridges over troubled waters: an interdisciplinary framework for evaluating the interconnectedness within fragmented domestic flood risk management systems. J Water Law 25(1):12-26

Green WA (1995) Periodizing world history. Hist Theory 34(2):99-111

Gregory D, Johnston R, Pratt G, Watts MJ, Whatmore S (eds) (2009) The dictionary of human geography. Wiley-Blackwell, Oxford

Gunderson L, Holling CS (eds) (2002) Panarchy: understanding transformations in human and natural systems. Island Press, Washington, DC

Gurevic AJ (1985) Categories of medieval culture. Routledge and Keegan Paul, London

Gusyev M, Gädeke A, Cullmann J, Magome J, Sugiura A, Sawano H, Takeuchi K (2016) Connecting global- and local-scale flood risk assessment: a case of the Rhine River basin flood hazard. J Flood Risk Manag 9(4):343-354

Hägerstrand T (1970) What about people in regional science? Pap Reg Sci Assoc 24(1):6-21

Hanna S, Jentoft S (1996) Human use of the natural environment: an overview of social and economic dimensions. In: Hanna S, Folke C, Maler KG (eds) Rights to nature. Island Press, Washington, DC, pp 35-55 
Hartmann T, Juepner R (2014) The flood risk management plan: an essential step towards the institutionalization of a paradigm shift. Int J Water Gov 2(1):107-118

Harvey D (1989) The condition of postmodernity. Blackwell Publishers, Hoboken, NJ, USA

Huesker F, Moss T (2015) The politics of multi-scalar action in river basin management: implementing the EU Water Framework Directive (WFD). Land Use Policy 42:38-47

Herod A (2003) Scale: the local and the global. In: Holloway SL, Rice SP, Valentine G (eds) Key concepts in geography. SAGE Publications, London/Thousand Oaks, pp 229-246

Jager NW, Challies E et al (2016) Transforming European water governance? Participation and river basin management under the EU Water Framework Directive in 13 member states. Water 8(4): 156

Lindblom C (1959) The science of "muddling through". Public Adm Rev 19(2):79-88

Lynch K (1960) The image of the city. MIT Press, Cambridge, MA

Marston SA, Jones JP III, Woodward W (2005) Human geography without scale. Trans Inst Br Geogr 30:416-432

Mayhew S (2015) Oxford dictionary of geography. Oxford University Press, Oxford

Moss T, Newig J (2010) Multilevel water governance and problems of scale: setting the stage for a broader debate. Environ Manag 46:1-6

Muhar S, Januschke K, Kail J, Poppe M, Schmutz S, Hering D, Buijse AD (2016) Evaluating goodpractice cases for river restoration across Europe: context, methodological framework, selected results and recommendations. Hydrobiologia 769(1):3-19

Nesshöver C, Assmuth T, Irvine KN, Rusch GM, Waylen KA, Delbaere B, Haase D, Jones-Walters L, Keune H, Kovacs E, Krauze K, Külvik M, Rey F, Van Dijk J, Vistad OI, Wilkinson ME, Wittmer H (2017) The science, policy and practice of nature-based solutions: an interdisciplinary perspective. Sci Total Environ 579:1215-1227

Office of Environment and Heritage (OEH) (2017) A proposed new legal framework: aboriginal cultural heritage in NSW. OEH, Sydney

Rand J, Hoen B (2017) Thirty years of North American wind energy acceptance research: what have we learned? Energy Res Soc Sci 29:135-148

Schanze J (2017) Nature-based solutions in flood risk management—buzzword or innovation? J Flood Risk Manag 10:281-282

Schumm SA (1994) Erroneous perceptions of fluvial hazards. Geomorphology 10:129-138

Schumm SA, Lichty RW (1965) Time, space, and causality in geomorphology. Am J Sci 263(2):110-119

Sheehan J (2014) The effects of sea level rise and increased storm events: an editorial introduction. Geogr Res Forum 34:1-8

Slavíková L, Raška P, Kopáček M (2019) Mayors and “their" land: revealing approaches to flood risk management in small municipalities. J Flood Risk Manag e12474 (in press)

Termeer CJAM, Dewulf A, van Lieshout M (2010) Disentangling scale approaches in governance research: comparing monocentric, multilevel, and adaptive governance. Ecol Soc 15(4)

Wilbanks T, Kates RW (1999) Global change in local places. How scale matters. Clim Change 43:601-628

Young OR (2002) The institutional dimensions of environmental change: fit, interplay, and scale (global environmental accords: strategies for sustainability). MIT Press, Cumberland

Ženka J, Novotný J, Slach O, Květoň V (2015) Industrial specialization and economic performance: a case of Czech microregions. Nor J Geogr 69(2):67-79

Zevenbergen C, Veerbeek W, Gersoniu B, Van Herk S (2008) Challenges in urban flood management: travelling across spatial and temporal scales. J Flood Risk Manag 1(2):81-88 
Pavel Raška (*1982) graduated from JEP University (history and geography) and Masaryk University (physical geography). He is currently Associate Professor and Head at the Department of Geography, Faculty of Science, J. E. Purkyně University in Ústí nad Labem. His main research interests include flood hazards and risk reduction, in which he explores interdisciplinary perspectives on institutional barriers to FRM and planning.

Lenka Slavíková graduated from University of Economics, Prague (public economics and policy). Currently, she serves as the Associate Professor at the Faculty of Social and Economic Studies J. E. Purkyně University in Ustí nad Labem. Her long-term interest is in water and biodiversity governance with the focus on Central and Eastern European Countries. She investigates flood risk perception of different actors and financial instruments for flood recovery and mitigation.

John Sheehan currently Adjunct Professor in the Faculty of Design Architecture and Building. He is also Adjunct Professor in the Faculty of Society and Design at Bond University, Gold Coast, Queensland. In 2017, John was appointed Guest Professor with the Institute for Economic and Environmental Policy (IEEP) in the Faculty of Social and Economic Studies at J. E. Purkyně University in Usti nad Labem, Czech Republic. In 2003 he was appointed the independent Chair of the Project Advisory Committee Water Property Titles Program, Land and Water Australia, which was a research project funded by the Commonwealth Government to establish a water titling system for Australia.

Open Access This chapter is licensed under the terms of the Creative Commons Attribution 4.0 International License (http://creativecommons.org/licenses/by/4.0/), which permits use, sharing, adaptation, distribution and reproduction in any medium or format, as long as you give appropriate credit to the original author(s) and the source, provide a link to the Creative Commons license and indicate if changes were made.

The images or other third party material in this chapter are included in the chapter's Creative Commons license, unless indicated otherwise in a credit line to the material. If material is not included in the chapter's Creative Commons license and your intended use is not permitted by statutory regulation or exceeds the permitted use, you will need to obtain permission directly from the copyright holder.

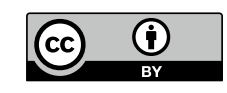

